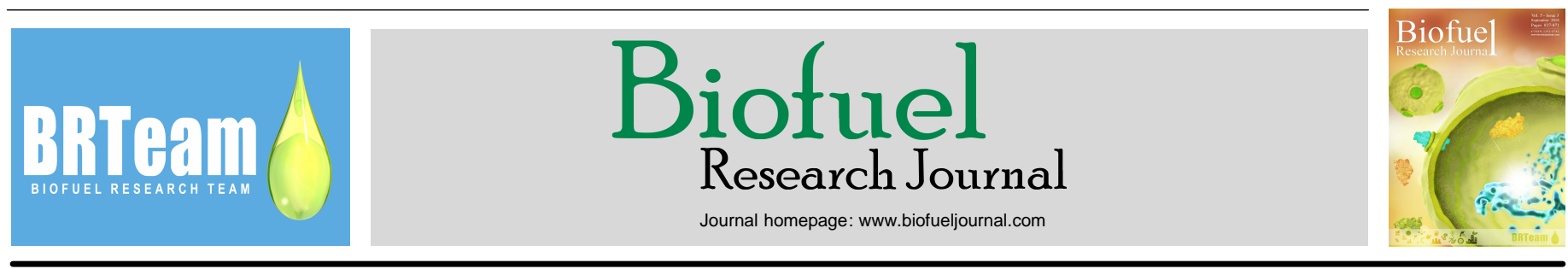

Original Research Paper

\title{
Enzymatic hydrolysis of biologically pretreated sorghum husk for bioethanol production
}

Pankajkumar R. Waghmare ${ }^{1,2}$, Rahul V. Khandare ${ }^{3}$, Byong-Hun Jeon ${ }^{4}$, Sanjay P. Govindwar ${ }^{1,4, *}$

${ }^{1}$ Department of Biochemistry, Shivaji University, Vidyanagar, Kolhapur 416004, Maharashtra, India.

${ }^{2}$ State Key Laboratory of Microbial Technology, Shandong University, Qingdao 266237, Shandong, China.

${ }^{3}$ Amity Institute of Biotechnology, Amity University, Mumbai, India 410206.

${ }^{4}$ Department of Earth Resources and Environmental Engineering, Hanyang University, Seoul 04763, South Korea.

\section{HIGHLIGHTS}

$>$ Biological pretreatment of sorghum husk using Phanerochaete chrysosporium was investigated. evaluated.

$>$ Significant increase in reducing sugar production as a result of biological pretreatment of sorghum husk vs. untreated biomass.

$>$ Biological pretreatment led to substantial surface morphological changes. $>$ Activities of different ligninolytic and hydrolytic enzymes during biological pretreatment were

\section{GRAPHICAL ABSTRACT}

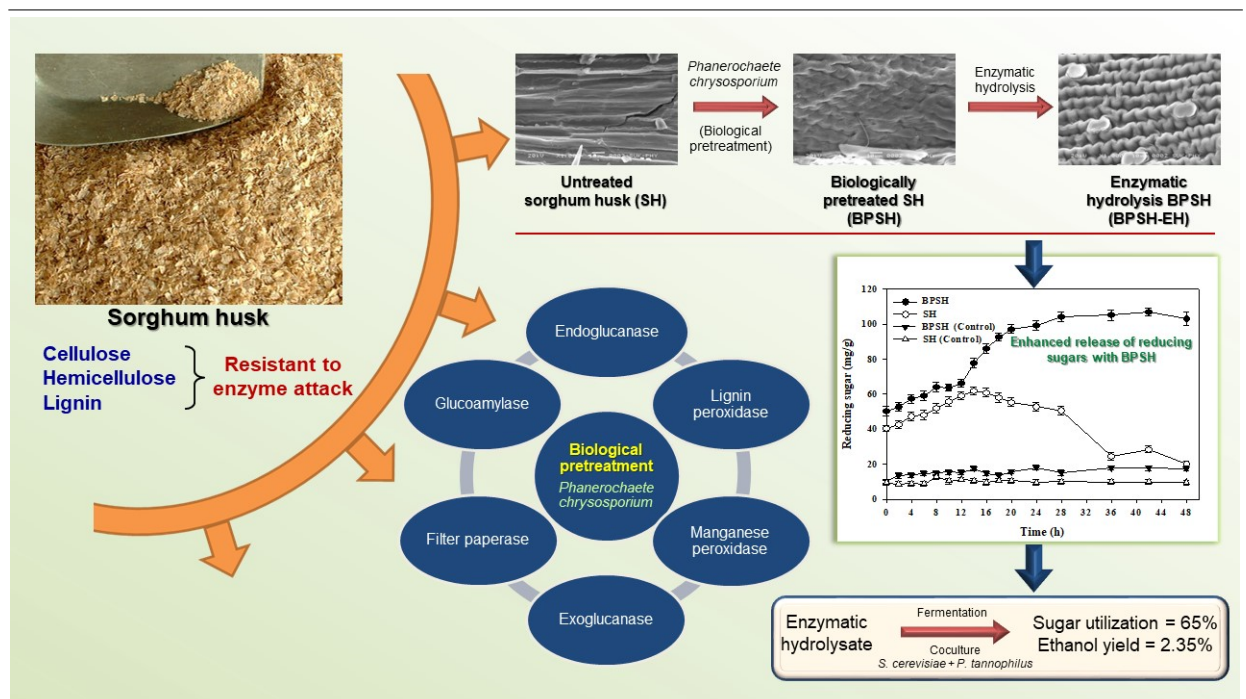

\section{ARTICLE INFO}

\section{Article history:}

Received 18 June 2018

Received in revised form 10 August 2018

Accepted 13 August 2018

Available online 1 September 2018

\section{Keywords:}

Sorghum husk

Phanerochaete chrysosporium

Delignification

Biological pretreatment

Enzymatic hydrolysis

Ethanol production

\begin{abstract}
Biological pretreatment of lignocellulosic biomass is considered to be energy-efficient and cost-effective. In the present study, sorghum husk was biologically pretreated with a white-rot fungus Phanerochaete chrysosporium (MTCC 4955) under submerged static condition. Ligninolytic enzymes like lignin peroxidase $(0.843 \mathrm{U} / \mathrm{mL})$ and manganese peroxidase $(0.389 \mathrm{U} / \mathrm{mL})$ played an important role in the biological pretreatment of sorghum husk. Activities of different hydrolytic enzymes such as endoglucanase $(57.25 \mathrm{U} / \mathrm{mL})$, exoglucanase $(4.76 \mathrm{U} / \mathrm{mL})$, filter paperase $(0.580 \mathrm{U} / \mathrm{mL})$, glucoamylase $(153.38 \mathrm{U} / \mathrm{mL})$, and xylanase $(88.14 \mathrm{U} / \mathrm{mL})$ during biological pretreatment of sorghum husk by $P$. chrysosporium were evaluated. Enzymatic hydrolysis of untreated sorghum husk and biologically pretreated sorghum husk produced 20.07 and $103.0 \mathrm{mg} / \mathrm{g}$ reducing sugars, respectively. This result showed a significant increase in reducing sugar production in the biologically pretreated sorghum husk as compared to its untreated counterpart. Biologically pretreated sorghum husk hydrolysate was further fermented for $48 \mathrm{~h}$ using Saccharomyces cerevisiae (KCTC 7296), Pachysolen tannophilus (MTCC 1077), and their co-culture resulting in ethanol yields of $2.113,1.095$, and $2.348 \%$, respectively. The surface characteristics of the substrate were evaluated after the delignification and hydrolysis, using FTIR, XRD, and SEM, confirming the effectiveness of the biological pretreatment process.
\end{abstract}

(C) 2018 BRTeam. All rights reserved.

* Corresponding author at: Tel.: +91 9822840094

E-mail address: spgovindwar@hanyang.ac.kr

Please cite this article as: Waghmare P.R., Khandare R.V., Jeon B.H., Govindwar S.P. Enzymatic hydrolysis of biologically pretreated sorghum husk for bioethanol production. Biofuel Research Journal 19 (2018) 846-853. DOI: 10.18331/BRJ2018.5.3.4 


\section{Introduction}

Global energy demand and consumption are continuously increasing with the rapidly growing world population. This has resulted in a grave depletion of fossil-fuel reservoirs (Bateni et al., 2017; Velazquez-Lucio et al., 2018). Therefore, recent research interests have been focused towards the generation of alternative and eco-friendly energy sources (Saritha et al., 2012; Bateni and Karimi, 2016). Plants fix atmospheric $\mathrm{CO}_{2}$ through photosynthesis and produce lignocellulosic complexes recycling about $10^{11}$ tons of carbon annually (Yeoman et al., 2010). First-generation biofuels are widely criticized because of issues like threats to global food security and staples' market prices (Keeney and Hertel, 2009). The transition from first to second generation biofuels resulted in replacement of food crops by lignocellulosic biomass (Fischer et al., 2009). These biomasses are an abundantly available, renewable, and low cost feedstock on the renewable energy technology platform providing a great potential for production of second-generation biofuels (Sun and Cheng, 2002).

The lignocellulosic biomass is composed of densely packed cellulose, hemicellulose, and lignin structures forming a complex molecule which is highly resistant to enzymatic attack resulting in lower sugar yields after saccharification (Himmel et al., 2007; Bansal et al., 2012). The lignin part of this complex offers hydrophobicity and mechanical protection to plant cells (Sun and Cheng, 2002; Kumar et al., 2016). Thus, lignin becomes the major barrier for cellulose accessibility to cellulases during hydrolysis of lignocellulosic wastes. Lignin also acts as a binding site for irreversible adsorption of cellulase enzyme, resulting in cellulase deactivation (Gan et al., 2002; Zhang et al., 2010; Noori and Karimi, 2015). This will consequently, results in a lower sugar release from enzymatic saccharification and finally less ethanol yields. Thus, pretreatments are required to effectively remove lignin, reduce cellulose crystallinity, increase cellulase accessibility, and consequently improve bioconversion of lignocellulosic substrates (Singh and Chen, 2008; Bansal et al., 2012).

The conventional physical, chemical, and thermal pretreatment processes suffer from major drawbacks such as selectivity, energy intensiveness, and production of effluents and residues causing environmental pollution (Zeng et al., 2011). The toxic chemicals such as furfural and hydroxymethylfurfural produced during conventional pretreatments also inhibit enzyme activities during hydrolysis (Mosier et al., 2005; Taherzadeh and Karimi, 2007). On the other hand, biological pretreatment is considered as an environmentally friendly approach which requires lower energy and thus, decreases pretreatment cost (Sindhu et al., 2016; Bateni et al., 2017). Additionally, it helps to reduce the release of pollutants and improve hydrolysis of lignocellulosic biomass at lower costs (Saritha et al., 2012; Sindhu et al., 2016). Various detoxification steps used for the removal of the inhibitors formed during conventional pretreatments can also be eliminated using biological pretreatment (Taherzadeh and Karimi 2008; Sindhu et al., 2016). Microbial enzymes degrade lignin and hemicellulose components contained in lignocellulosic biomass during biological pretreatment (Saritha et al., 2012; Bateni et al., 2017). A number of previous studies have suggested the effectiveness of white-rot fungi for biological pretreatment of lignocellulosic biomass (Fan et al., 1987). White-rot fungus Phanerochaete chrysosporium has a promising potential for lignin degradation by releasing proper enzymes including lignin peroxidase $(\mathrm{LiP})$ and manganese peroxidase $(\mathrm{MnP})$ (Lee et al., 2006). White-rots have been specially recognized for their selectivity towards decomposition of lignocellulosic biomass (Yu et al., 2009).

In this work, sorghum husk (SH) was biologically pretreated by the ligninolytic enzymes produced by $P$. chrysosporium (MTCC 4955). At the same time, cellulolytic enzymes were also produced in the hydrolysate. This byproduct was further utilized as a crude enzyme for saccharification of SH. Fourier Transform Infrared Spectroscopy (FTIR), X-ray Diffraction (XRD), and Scanning Electron Microscopy (SEM) were used to study the changes in the surface topology of the substrate after pretreatment and hydrolysis. Finally, the sugars released in the hydrolysate were converted into ethanol using Saccharomyces cerevisiae (KCTC 7296) and Pachysolen tannophilus (MTCC 1077). It should be noted that agricultural wastes like SH generated after threshing processes could provide an avenue for the scientific community of the developing countries like India to have a look at bioenergy horizon in order to opt for a promising eco-friendly perspective.

\section{Materials and Methods}

\subsection{Lignocellulosic biomass}

SH (Sorghum vulgare) was collected from a local agricultural farm near Kolhapur, India. The collected biomass was air-dried in an oven and milled using a pulverizer, ground to particle size $<1 \mathrm{~mm}$, and stored under moisture-free conditions at $37^{\circ} \mathrm{C}$, until further experiments.

\subsection{Biological pretreatment of $S H$}

Fifteen grams of air-dried SH was taken in $300 \mathrm{~mL}$ Dubos medium $(\mathrm{g} / \mathrm{L}$ : $\mathrm{NaNO}_{3}, 0.5 ; \mathrm{K}_{2} \mathrm{HPO}_{4}, 1.0 ; \mathrm{MgSO}_{4} .7 \mathrm{H}_{2} \mathrm{O}, 0.5 ; \mathrm{KCl}, 0.5 ; \mathrm{FeSO}_{4} .7 \mathrm{H}_{2} \mathrm{O}$ 0.001 ) and pretreated with white-rot fungus $P$. chrysosporium (MTCC 4955) under submerged static condition at $30{ }^{\circ} \mathrm{C}$. The ligninolytic enzymes were produced by $P$. chrysosporium (MTCC 4955) during the biological pretreatment. The activity of $\mathrm{LiP}$ and $\mathrm{MnP}$ were monitored for up to $10 \mathrm{~d}$ of the incubation. One unit of LiP activity was defined as the amount of the enzyme that led to the production of $1 \mu \mathrm{moL}$ veratryl aldehyde from the oxidation of veratryl alcohol per min (Liu et al., 2008). One unit of MnP activity was expressed as the amount of enzyme that led to the production of $1 \mu \mathrm{moL} \mathrm{Mn}{ }^{3+}$ from the oxidation of $\mathrm{Mn}^{2+}$ per min (Rogalski et al., 2006). The biologically pretreated SH (BPSH) was collected by centrifugation at $5000 \mathrm{rpm}$ for $10 \mathrm{~min}$ after $8 \mathrm{~d}$ of the incubation. The substrate was then washed with distilled water, oven dried at $37^{\circ} \mathrm{C}$ and stored under moisturefree conditions until further study.

\subsection{Composition analysis}

Acid detergent lignin (ADL) and acid detergent fiber (ADF) were determined using the AOAC standard method 973.18 (AOAC, 1990a). The neutral detergent fiber (NDF) was determined using the method reported by van Soest et al. (1991). Total ash content was determined by using the AOAC standard method 942.05 (AOAC, 1990b). Cellulose percentage was calculated indirectly from ADF and lignin (ADF minus lignin) (Mani et al. 2006). Hemicellulose percentage was calculated indirectly from NDF and ADF (NDF minus ADF) (Mani et al., 2006).

\subsection{Fungal crude enzyme preparation}

P. chrysosporium fermented broth was collected on the $8 \mathrm{~d}$ of incubation and the supernatant was obtained by centrifugation at $5000 \mathrm{rpm}$ for $10 \mathrm{~min}$. The supernatant was filtered through a $0.45 \mu \mathrm{m}$ polyethersulfone membrane filter and was further concentrated with ultracentrifugation. The concentrated broth was used as crude enzyme source for enzymatic hydrolysis of SH feedstock.

\subsection{Enzyme analysis}

The cellulolytic enzyme activities such as filter paperase activity (FPU) (Adney and Baker, 2008), endoglucanase, and exoglucanase (Nitisinprasert and Temmes, 1991), as well as hemicellulolytic enzyme activities like glucoamylase and xylanase (Saratale et al., 2012) were determined after 8 $\mathrm{d}$ of incubation. One unit of enzyme activity was defined as the amount of enzyme that produces $1 \mu \mathrm{moL}$ of reducing sugar from the substrate per min.

\subsection{Enzymatic saccharification of SH and BPSH}

The feedstock $(10 \%)$ was incubated with different crude enzyme dosages (i.e., 1, 2, 4, 5, and $10 \mathrm{FPU} / \mathrm{g}$ of feedstock) with $20 \mathrm{~mL}$ citrate buffer (50 mM, pH 4.8) in $100 \mathrm{~mL}$ Erlenmeyer flasks. The hydrolysis was performed at $50{ }^{\circ} \mathrm{C}$ and $110 \mathrm{rpm}$ for $48 \mathrm{~h}$ and the samples were collected every $2 \mathrm{~h}$. The collected samples were centrifuged to remove the unhydrolyzed residues. The supernatant was then heated for $5 \mathrm{~min}$ in a boiling water bath to deactivate cellulolytic enzymes. The reducing sugar was determined using the dinitrosalicylic acid (DNS) method (Miller, 1959). Hydrolysis yield was calculated using Equation 1 (Chen et al., 2007): 
Hydrolysis yield $(\%)=\frac{\text { Sugar Concentration } \times 0.9 \times 100}{\text { Polysaccharide content in substrate }}$

\subsection{Fermentation of hydrolysate}

S. cerevisiae and P. tannophilus were cultured separately in the medium containing g/L: malt extract 3.0; glucose 10; yeast extract 3.0, and peptone 5.0 in deionized water. Freshly grown yeast cells incubated up to $36 \mathrm{~h}$ at $30{ }^{\circ} \mathrm{C}$ were collected and washed with $0.1 \%$ peptone water to remove the residual media. The enzymatic hydrolysates of SH and BPSH were concentrated to reducing sugar concentration of $5 \%$ by evaporation at $80{ }^{\circ} \mathrm{C}$ and were supplemented with g/L: yeast extract 50; $\left(\mathrm{NH}_{4}\right)_{2} \mathrm{SO}_{4} 100 ; \mathrm{KH}_{2} \mathrm{PO}_{4} 45$ and $\mathrm{MgSO}_{4} \cdot 7 \mathrm{H}_{2} \mathrm{O}$ 10. Separate fermentation was performed for each yeast $S$. cerevisiae and $P$. tannophilus, adding $5 \%(\mathrm{v} / \mathrm{v})$ of inoculum. While cofermentation was performed by co-inoculation of both yeasts $(1: 1, v / v)$ in the medium supplemented with yeast extract. The fermentation was carried out up to $48 \mathrm{~h}$ at $30{ }^{\circ} \mathrm{C}$. The ethanol concentration of the fermented broth was determined by the $\mathrm{K}_{2} \mathrm{Cr}_{2} \mathrm{O}_{7}$ method (Williams and Reese, 1950) while the residual sugar contents were determined by the DNS method (Miller, 1959).

The yield of ethanol after fermentation expressed as a percentage of theoretical maximum ethanol yields was calculated using Equation 2 (Kim and Lee, 2005):

$\%$ Ethanol yield $=\frac{\text { Ethanol produced }(\mathrm{g}) \text { in fermented broth }}{\text { Reducing sugar concentration in fermented broth } \times 0.511} \times 100$

The reducing sugar utilization ratio and the amount of residual reducing sugar were determined after fermentation of SH hydrolysate by $\mathrm{S}$. cerevisiae and $P$. tannophilus. The fermentation efficiency was measured from the reducing sugar utilization ratio by using Equation 3 (Su et al., 2010).

Reducing sugar utilization ratio $(\%)=$

Reducing sugar yield after hydrolysis - Residual reducing after fermentation Reducing sugar yields after hydrolysis $\times 100$

\subsection{Surface characterization}

FTIR analysis was carried out for detection of changes in functional groups due to biological pretreatment and enzymatic hydrolysis. FTIR spectra were recorded on a FTIR spectrometer (Agilent, Cary 630; USA) in the absorption band mode in the range of $650-4000 \mathrm{~cm}^{-1}$ with a resolution of $4 \mathrm{~cm}^{-1}$ and 32 scans. The IR crystallinity of cellulose in lignocellulosic biomass was evaluated by $I R$ absorption ratios between the absorbance intensities $1375-1512 \mathrm{~cm}^{-1}$, $1429-897 \mathrm{~cm}^{-1}, 1372-2900 \mathrm{~cm}^{-1}, 1225-1736 \mathrm{~cm}^{-1}$, and $895-1510 \mathrm{~cm}^{-1}$.

Untreated SH, BPSH, SH residue post enzymatic hydrolysis (SH-EH), and BPSH residue post enzymatic hydrolysis (BPSH-EH) were analyzed with XRD, BRUKER (Germany), D2-Phaser set at $30 \mathrm{kV}, 10 \mathrm{~mA}$; radiation was $\mathrm{Cu}$ $\mathrm{K} \alpha(0.15418 \mathrm{~nm})$, and grade range between 10 and $40^{\circ}$ with a step size of $0.02^{\circ}$. Crystallinity index (CrI) of cellulose was calculated according to the peak intensity method using Equation 4 (Segal et al., 1959).

$\operatorname{CrI}(\%)=\frac{\mathrm{I}_{002}-\mathrm{I}_{\mathrm{am}}}{\mathrm{I}_{002}} \times 100$

Where, $\mathrm{CrI}$ is the crystallinity index, $\mathrm{I}_{002}$ is the maximum intensity at $2 \theta=$ $22.5^{\circ}$, and $\mathrm{I}_{\mathrm{am}}$ is the minimum intensity corresponding to the amorphous content at $2 \theta=18.0^{\circ}$.

The degree of crystallinity $\left(\mathrm{X}_{\mathrm{c}}\right)$ was calculated using Equation $\mathbf{5}$ (Zhou et al., 2005).

$\mathrm{X}_{\mathrm{c}}=\frac{\mathrm{F}_{\mathrm{c}}}{\mathrm{F}_{\mathrm{a}}+\mathrm{F}_{\mathrm{c}}} \times 100$

Where, $F_{c}$ and $F_{a}$ are the area of crystalline and non-crystalline regions, respectively.
The crystallite size of cellulose present in SH was calculated using the Scherrer equation (Eq. 6) (French and Cintrón, 2012).

$\mathrm{D}=\frac{\mathrm{k} \lambda}{\beta_{0} \times \cos \theta}$

Where $D$ is the size of crystallite $(\mathrm{nm}), k$ is the Scherrer constant $(0.94)$, $\lambda$ is the X-ray wavelength $(0.15418 \mathrm{~nm}$ for $\mathrm{Cu} \mathrm{K \alpha}), \beta_{0}$ denotes the fullwidth at half-maximum in radian, and $\theta$ stands for the position of the peak (half of the plotted $2 \theta$ value).

Changes in the surface topology and characterization of SH, BPSH, and BPSH-EH were visualized by SEM. Images of the surfaces of SH, BPSH, and BPSH-EH were taken at different magnifications, i.e., 500×, 1000× and 5000x using a JEOL JSM-6360 SEM. The substrate specimen was mounted on a conductive carbon tape and further coated with conductive gold. The gold-coated mounted sample was then scanned using $20 \mathrm{kV}$ accelerating voltage.

\subsection{Statistical analysis}

Data were analyzed using one-way analysis of variance (ANOVA) with Tukey-Kramer multiple comparison test with the help of GraphPad InStat version 3.06 software.

\section{Results and Discussion}

\subsection{Biological pretreatment of $S H$}

White-rot fungi are well-known for producing ligninolytic enzymes and thus, they play an important role in delignification of lignocellulosic biomass. P. chrysosporium (MTCC 4955) used for biological pretreatment of $\mathrm{SH}$ showed significant activities of $\mathrm{LiP}(0.843 \mathrm{U} / \mathrm{mL})$ and $\mathrm{MnP}(0.386$ $\mathrm{U} / \mathrm{mL}$ ) after $8 \mathrm{~d}$ of incubation. Changes in the composition of SH and BPSH were determined by the AOAC method as shown in Table 1 . Biological pretreatment of $\mathrm{SH}$ using $P$. chrysosporium resulted into $26 \%$ lignin removal (Table 1) yielding BPSH. Taniguchi et al. (2005) reported removal of $21 \%$ Kalson lignin from rice straw after biological pretreatment using white-rot fungus $P$. chrysosporium.

Table 1.

Composition of untreated sorghum husk (SH) and biologically pretreated SH (BPSH).

\begin{tabular}{lll}
\hline Component & SH $(\%, w / w)$ & BPSH $(\%, w / w)$ \\
\hline Cellulose & $40.2 \pm 0.72$ & $43.8 \pm 0.63$ \\
Hemicellulose & $41.2 \pm 0.40$ & $40.4 \pm 0.61$ \\
Lignin & $14.6 \pm 0.75$ & $10.8 \pm 0.53$ \\
Ash & $4 \pm 0.11$ & $5 \pm 0.20$ \\
\hline
\end{tabular}

\subsection{Enzyme analysis}

During the biological pretreatment, $P$. chrysosporium also produced different cellulolytic and hemicellulolytic enzymes utilizing SH as a carbon source. P. chrysosporium showed the maximum FPU activity of 0.580 $\mathrm{U} / \mathrm{mL}$ when grown on $\mathrm{SH}$ for $8 \mathrm{~d}$ after incubation. The crude filtrate showed noteworthy activities of the cellulolytic enzymes such as endoglucanase $(57.25 \mathrm{U} / \mathrm{mL})$, exoglucanase $(4.76 \mathrm{U} / \mathrm{mL}), \beta$-glucosidase $(15.48 \mathrm{U} / \mathrm{mL})$, as well as the hemicellulolytic enzyme activities like glucoamylase (153.38 $\mathrm{U} / \mathrm{mL}$ ) and xylanase $(88.14 \mathrm{U} / \mathrm{mL}$ ) (Table 2). Waghmare et al. (2014) reported the production of $0.128 \mathrm{U} / \mathrm{mL}$ FPU activity by $P$. chrysosporium using SH as carbon source. Saratale et al. (2015) also claimed a similar induction in the enzyme activities as endoglucanase (212.78 units/gram dry solid (U/gds)), exoglucanase (22.34 U/gds), cellobiase (176.50 U/gds), 
FPU (26.20 U/gds), and xylanase (371 U/gds) by P. chrysosporium utilizing soybean straw.

Table 2.

Enzymes produced by $P$. chrysosporium (MTCC 4955) after $8 \mathrm{~d}$ of incubation.

\begin{tabular}{ll}
\hline Cellulolytic enzymes & Enzyme activity $(\mathbf{U} / \mathbf{m L})$ \\
\hline Endoglucanase & $57.25 \pm 1.974 *$ \\
Exoglucanase & $4.76 \pm 0.266$ \\
FPU & $0.576 \pm 0.025$ \\
\hline Hemicellulolytic enzymes & Enzyme activity $(\mathbf{U} / \mathbf{m L})$ \\
\hline Glucoamylase & $126.22 \pm 3.021$ \\
Xylanase & $65.31 \pm 1.871$ \\
\hline Ligninolytic enzymes & Enzyme activity $(\mathbf{U} / \mathbf{m L})$ \\
\hline Lignin peroxidase & $0.843 \pm 0.014$ \\
Manganese peroxidase & $0.389 \pm 0.022$ \\
\hline * Values are mean of three experiments \pm SEM, and were obtained by \\
one-way ANOVA with Tukey-Kramer multiple comparisons test.
\end{tabular}

\subsection{Enzymatic saccharification of SH and BPSH}

Enzymatic hydrolysis is considered as the most crucial step in biofuels production from lignocellulosic biomass after pretreatment process (Noori and Karimi, 2016). Significant hydrolytic activity was observed with the crude enzyme from $P$. chrysosporium. Figure 1 shows the production of reducing sugars from SH and BPSH due to hydrolytic activities of the crude enzyme. Enzymatic hydrolysis of SH and BPSH did not show any significant differences in the reducing sugar production for the first $2 \mathrm{~h}$. Interestingly, the produced reducing sugar from SH and BPSH was increased up to $12 \mathrm{~h}$ of enzymatic hydrolysis while beyond that, the reducing sugar production was continuously decreased in the case of SH. This could be ascribed to the removal of lignin from SH during biological pretreatment which decreased the irreversible cellulase adsorption. Thus, during the enzymatic hydrolysis of SH, adsorption of cellulase on lignin might have caused an unavailability of cellulase to produce reducing sugar.

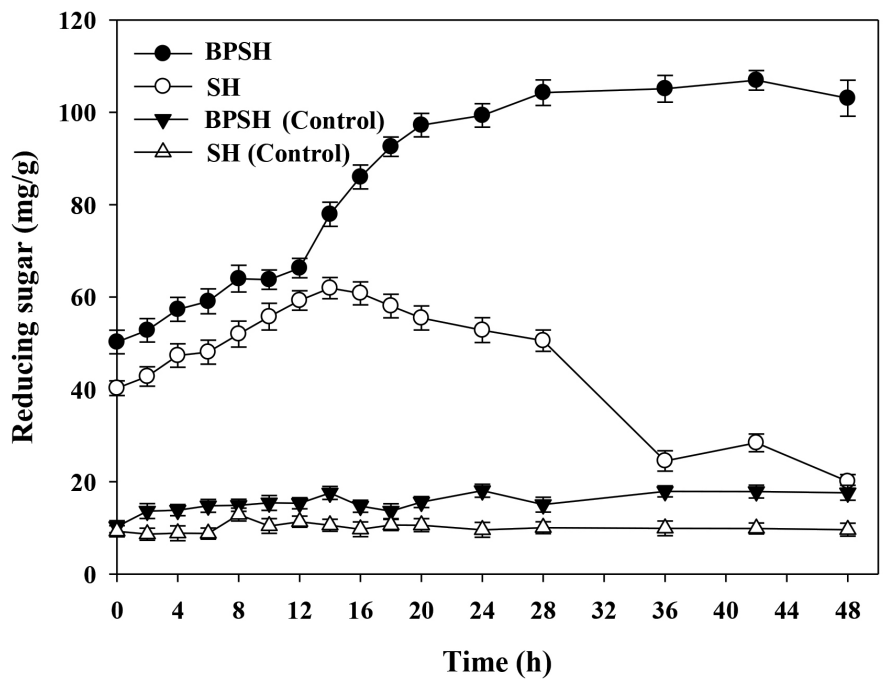

Fig.1. Enzymatic hydrolysis of untreated sorghum husk (SH) and biologically pretreated sorghum husk (BPSH) using $5 \mathrm{FPU} / \mathrm{g}$ cellulase dosage of crude enzyme produced by $P$. chrysosporium (MTCC 4955) fungi. In the hydrolysis reaction, the control BPSH and SH contained $50 \mathrm{mM}$ citrate buffer ( $\mathrm{pH} 4.8)$.
At the end of the enzymatic hydrolysis experiment ( $48 \mathrm{~h})$, the reducing sugar produced from the hydrolysis of $\mathrm{SH}(20.07 \mathrm{mg} / \mathrm{g})$ was lower than that of BPSH (103.0 mg/g) (Fig. 1). This difference in reducing sugar production during enzymatic hydrolysis of $\mathrm{SH}$ and $\mathrm{BPSH}$ must have occurred because of delignification during biological pretreatment by $P$. chrysosporium. Waghmare et al. (2014) reported a release of $0.30 \mathrm{mg} / \mathrm{g}$ reducing sugar after saccharification of biologically pretreated sugarcane bagasse.

Cellulase contributes a significant fraction of the total cost of biomass conversion process (Cao et al., 1996). Therefore, for cost effectiveness, the use of lower cellulase dosage during enzymatic hydrolysis is desirable. Different enzyme dosages were determined as FPU activity of crude enzyme during the enzymatic hydrolysis experiments. A significantly higher hydrolysis yields of $40 \%$ (BPSH) and 10\% (SH) were observed when $5 \mathrm{FPU} / \mathrm{g}$ crude cellulase dosage was used. The hydrolysis yields for BPSH and SH using other cellulase dosages of 1, 2, and 4 FPU/g were found to be lower than of $5 \mathrm{FPU} / \mathrm{g}$. Values were not significantly higher in the case of the cellulase dosage of $10 \mathrm{FPU} / \mathrm{g}$ compared with those of 5 FPU/g (Table 3). Thus, the hydrolysate produced using cellulase dosage of $5 \mathrm{FPU} / \mathrm{g}$ was studied further for cost effective fermentation. Kshirsagar et al. (2016) reported 60\% hydrolysis yield from enzymatic hydrolysis of wheat straw using crude enzyme from Amycolatopsis sp. GDS

Table 3.

Effect of different cellulase dosages on hydrolysis yield after enzymatic hydrolysis of untreated sorghum husk (SH) and biologically pretreated SH (BPSH).

\begin{tabular}{lcc}
\hline \multirow{2}{*}{ Cellulase dosage (FPU/g) } & \multicolumn{2}{c}{ Hydrolysis yield (\%) } \\
\cline { 2 - 3 } & BPSH & Untreated SH \\
\hline 1 & 8 & 3 \\
2 & 14 & 5 \\
4 & 25 & 8 \\
5 & 40 & 10 \\
10 & 42 & 11 \\
\hline
\end{tabular}

\subsection{Fermentation of hydrolysate}

The resulting enzymatic hydrolysate contained both pentose and hexose sugars. Thus, after fermentation by $S$. cerevisiae and $P$. tannophilus yeast strains, significant bioethanol concentrations were recorded. More specifically, ethanol concentrations of 2.113 and $1.095 \%$ were obtained with $S$. cerevisiae and $P$. tannophilus, respectively, from the BPSH hydrolysate. The ethanol concentration observed from separate yeast fermentation and co-fermentation of SH hydrolysate was very low and thus, economically non-significant. This difference in performances in ethanol production with the explored yeast strains was because of the preferential utilization of pentose and hexose sugar available in the hydrolysate (Havannavar and Geeta, 2007). In this study, the ethanol concentration of $2.348 \%$ was observed from the co-inoculated BPSH hydrolysate. The reducing sugar utilization ratios for fermentation by either of $S$. cerevisiae and $P$. tannophilus as well as their co-culture were found to be $56.57,58.92$, and $65.04 \%$, respectively, which was attributed to the combined utilization of sugars by $S$. cerevisiae and P. tannophilus. Similarly, a higher ethano production was reported using co-culture of C5- and C6-utilizing yeasts compared to those of individual yeast cultures (Jeffries et al., 2007; Singh and Bishnoi, 2012).

\subsection{Surface characterization of biomass with FTIR, XRD, and SEM}

FTIR analysis revealed the functional groups transformation of $\mathrm{SH}$ feedstock after biological pretreatment and further enzymatic hydrolysis. Comparative FTIR spectra of SH, BPSH, SH-EH, and BPSH-EH are shown in Figure 2. Most representative peaks are summarized as follows. The broad absorption bands at 3300 and $2900 \mathrm{~cm}^{-1}$ correspond to the $\mathrm{H}$-bond 


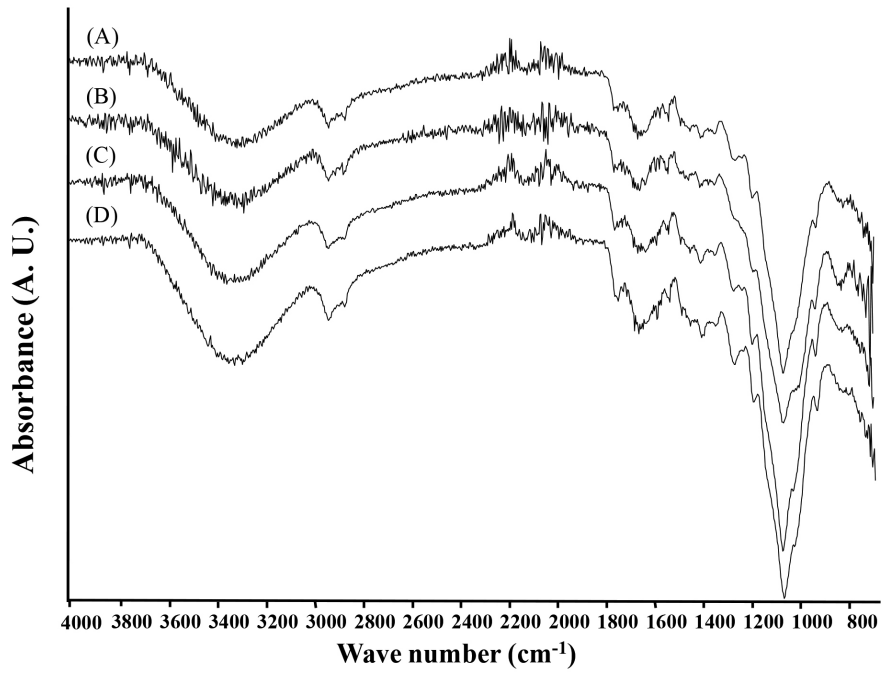

Fig.2. FTIR analysis revealing the functional group modifications in the substrate. (A) Untreated sorghum husk (SH); (B) Biologically pretreated SH (BPSH); (C) SH residue post enzymatic hydrolysis (SH-EH), and (D) BPSH residue post enzymatic hydrolysis (BPSH-EH).

stretching of $\mathrm{OH}$ groups and $\mathrm{C}-\mathrm{H}$ groups, respectively (Wang et al., 2007). The bands at 1736 and $1620 \mathrm{~cm}^{-1}$ correspond to carbonyl stretching $(\mathrm{C}=\mathrm{O})$ for acetyl groups of hemicelluloses and for aldehyde group present in lignin, respectively (Ramle et al., 2012). The band at $1510 \mathrm{~cm}^{-1}$ is associated with $\mathrm{C}=\mathrm{C}$ stretching of the aromatic ring of lignin (Lionetto et al., 2012). The band at 1430 and 1320 $\mathrm{cm}^{-1}$ revealed the symmetric $\mathrm{CH}_{2}$ bending and wagging (Binod et al., 2012) while the band at $1375 \mathrm{~cm}^{-1}$ showed C-H bending (Colom and Carrillo, 2002). The band at $1225 \mathrm{~cm}^{-1}$ was the bending of O-H (Oh et al., 2005). C-O-C stretching at the $\beta(1-4)$ glycoside linkages gave two peaks at 1160 and $895 \mathrm{~cm}^{-}$ ${ }^{1}$ (Oh et al., 2005). The band at $1033 \mathrm{~cm}^{-1}$ was indicative of C-O stretching at C-6. Major changes such as the elimination of peaks at 1225 and $1160 \mathrm{~cm}^{-1}$ assigned to $\mathrm{O}-\mathrm{H}$ bending and $\mathrm{C}-\mathrm{O}$ stretching, respectively, indicated functional group modification in $\mathrm{SH}$ after biological pretreatment.

In this study, IR ratios such as $A_{1375} / A_{1510}, A_{1427} / A_{895}, A_{1375} / A_{2900}$, and $\mathrm{A}_{895} / \mathrm{A}_{1510}$ were determined by the ratio of absorbance peaks 1375,$1512 ; 1429$, $897 ; 1372,2900$, and $895,1510 \mathrm{~cm}^{-1}$, respectively, and were calculated for SH, BPSH, SH-EH, and BPSH-EH samples. The peaks at 1730, 1427, 1375, 1158, and $895 \mathrm{~cm}^{-1}$ were not correspondent to lignin (Fackler et al., 2011), the relative intensities of lignin peaks at $1512 \mathrm{~cm}^{-1}$ against cellulose while peaks at 1375 and $895 \mathrm{~cm}^{-1}$ calculated using peak heights and areas, were used to evaluate the changes in SH during biological pretreatment and enzymatic hydrolysis.

Among these different IR ratios, $A_{1375} / A_{1510}$ is of importance for IR crystallinity determination as the peak at $1375 \mathrm{~cm}^{-1}$ corresponds to $\mathrm{C}-\mathrm{H}$ deformation in cellulose while the peak at $1510 \mathrm{~cm}^{-1}$ is associated to the aromatic skeletal vibration $\mathrm{C}=\mathrm{C}$ in lignin (Fackler et al., 2011). The IR crystallinity ratio $\mathrm{A}_{1375} / \mathrm{A}_{1510}$ was increased to 1.44 in the case of $\mathrm{BPSH}$ compared with 1.43 in BPSH-EH after biological pretreatment and enzymatic hydrolysis (Table 4). The IR ratio $\mathrm{A}_{895} / \mathrm{A}_{1510}$ is of importance as the peak at 895 $\mathrm{cm}^{-1}$ corresponds to $\mathrm{CH}$ deformation in cellulose (Yang et al., 2009). The $\mathrm{A}_{895} / \mathrm{A}_{1510}$ ratio was found to increase after biological pretreatment to 2.7 as compared to that of the untreated SH (2.31) while it decreased again to 2.21 in the case of BPSH-EH (Table 4). In addition, the $\mathrm{A}_{1375} / \mathrm{A}_{2900}$ ratio was decreased in crystallinity from SH (1.22) to BPSH-EH (1.12). This change in IR crystallinity in BPSH and BPSH-EH confirmed that removal of lignin and cellulose from untreated SH during biological pretreatment and enzymatic hydrolysis.

The XRD profiles of SH, BPSH, SH-EH, and BPSH-EH are shown in Figure 3 . The CrI, the degree of crystallinity, crystallite size, and number of chains of cellulose in the substrates were determined by using Equations 4, 5, and 6 , respectively. Because of the biological pretreatment, morphological changes were observed in cellulose structure. The CrI of cellulose is considered as one of the most important factors for determination of enzymatic hydrolysis efficiency. Therefore, $\mathrm{CrI}$ of cellulose has been observed for more than fifty
Table 4.

Effect of biological pretreatment and enzymatic hydrolysis on the IR crystallinity ratio of untreated sorghum husk ( $\mathrm{SH})$, biologically pretreated $\mathrm{SH}$ (BPSH), SH residue post enzymatic hydrolysis (SH-EH), and BPSH residue post enzymatic hydrolysis (BPSH-EH).

\begin{tabular}{lcccc}
\hline \multirow{2}{*}{ Sample type } & \multicolumn{4}{c}{ IR crystallinity ratio } \\
\cline { 2 - 5 } & $\mathbf{A}_{\mathbf{1 3 7 5}} / \mathbf{A}_{\mathbf{1 5 1 0}}$ & $\mathbf{A}_{\mathbf{1 4 1 2}} / \mathbf{A}_{\mathbf{8 9 5}}$ & $\mathbf{A}_{\mathbf{1 3 7 5}} / \mathbf{A}_{\mathbf{2 9 0 0}}$ & $\mathbf{A}_{\mathbf{8 9 5}} / \mathbf{A}_{\mathbf{1 5 1 0}}$ \\
\hline Untreated SH & 1.22 & 0.43 & 1.22 & 2.31 \\
BPSH & 1.44 & 0.36 & 1.00 & 2.7 \\
SH-EH & 1.43 & 0.47 & 1.27 & 3.37 \\
BPSH-EH & 1.43 & 0.53 & 1.12 & 2.21 \\
\hline
\end{tabular}

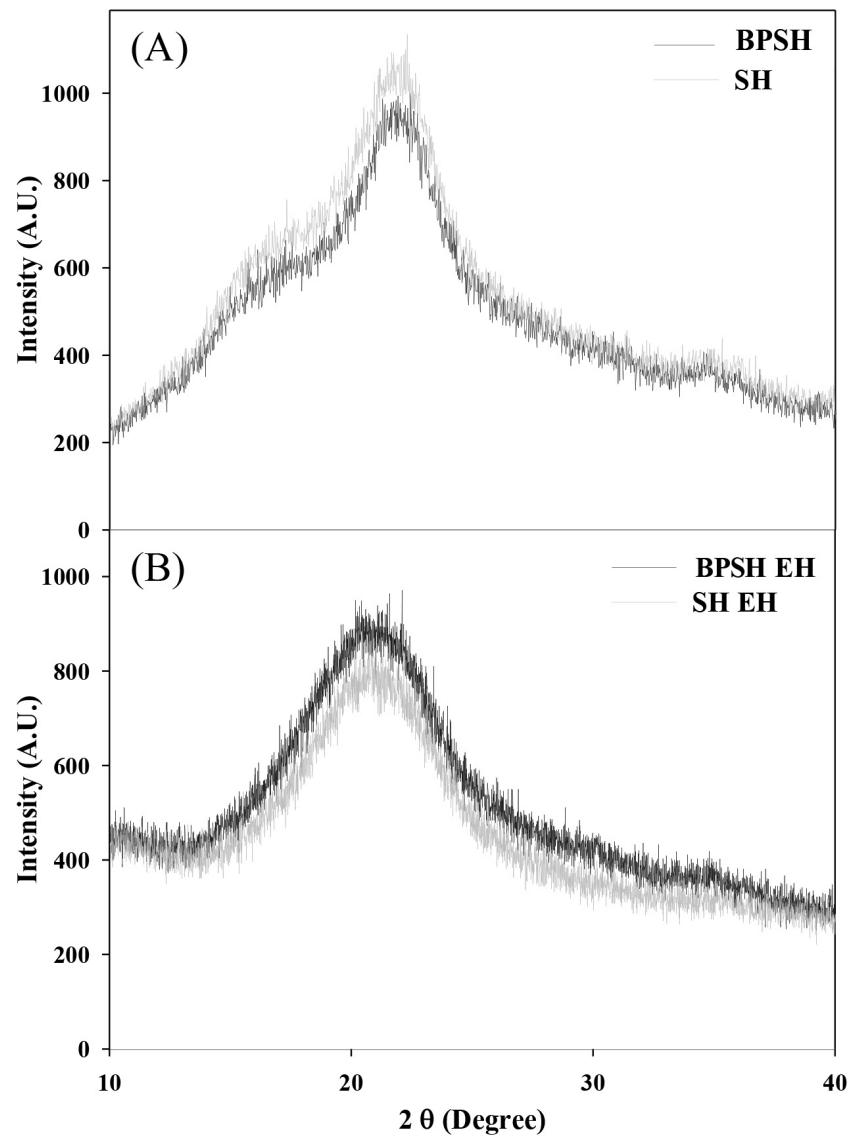

Fig.3. XRD analysis of the substrate after biological pretreatment and enzymatic hydrolysis. (A) Untreated sorghum husk (SH); (B) Biologically pretreated SH (BPSH); (C) SH residue post enzymatic hydrolysis (SH-EH), and (D) BPSH residue post enzymatic hydrolysis (BPSH-EH).

years for interpretation of change in cellulose structure due to the implementation of various pretreatment methods and enzymatic hydrolysis (Park et al., 2010). The CrI of SH (37.65\%) was found to be greater as compared to those of BPSH (32.84\%), SH-EH (20.36\%), and BPSH-EH $(17.98 \%)$ samples (Table 5 ). Similar pattern of decrease in crystallinity by XRD analysis is correlated to IR crystallinity ratio of $\mathrm{A}_{1375} / \mathrm{A}_{2900}$ (Karimi and Taherzadeh, 2016). This decrease in crystallinity of cellulose and the simultaneous increase in the numbers of pores size must have occurred due 
Table 5.

Crystallinity index, crystalline size, crystallinity degree, and the number of cellulose chains of untreated sorghum husk (SH), biologically pretreated SH (BPSH), SH residue post enzymatic hydrolysis (SH-EH), and BPSH residue post enzymatic hydrolysis (BPSH-EH).

\begin{tabular}{lcccc}
\hline Sample type & $\begin{array}{c}\text { Crystallinity } \\
\text { Index }(\boldsymbol{\%})\end{array}$ & $\begin{array}{c}\text { Crystalline } \\
\text { size }(\mathbf{n m})\end{array}$ & $\begin{array}{c}\text { Crystallinity } \\
\text { degree }(\boldsymbol{\%})\end{array}$ & $\begin{array}{c}\text { No. of cellulose } \\
\text { chains }^{*}\end{array}$ \\
\hline Untreated SH & 37.65 & 0.83 & 43.6 & 2.12 \\
BPSH & 32.84 & 0.73 & 40 & 1.87 \\
SH-EH & 20.36 & 1.31 & 72 & 3.35 \\
BPSH-EH & 17.98 & 1.20 & 67 & 3.07 \\
\hline
\end{tabular}

* The number of cellulose chains obtained by dividing the crystalline size by $0.39 \mathrm{~nm}$, the thickness of the cellulose chain.

to the removal of lignin in the case of BPSH (Lee et al., 2007; Millati et al., 2011). The SEM images of SH, BPSH, and BPSH-EH (Fig. 4) confirmed the surface morphological changes which occurred after biological pretreatment and enzymatic hydrolysis. SEM images of untreated SH (Fig. 4A, D, G) showed a complete, compact, and uninterrupted surface whereas the topology of BPSH was distorted (Fig. 4B, E, H). These changes in the surface topology could be due to the activity of ligninolytic enzymes produced by $P$. chrysosporium during biological pretreatment. The SEM images of BPSH-EH showed distinct and prominent roughness with deeper groves and looser topology (Fig. 4, C, F, I) as compared to the untreated SH. During the biological pretreatment, the external surface of the lignocellulosic biomass was damaged and the surface area for cellulose of SH became accessible to cellulases present in the crude enzyme. Taniguchi et al. (2005) conducted a pretreatment with Pleurotus ostreatus and reported an increase in the susceptibility of rice straw to enzymatic hydrolysis due to partial degradation of lignin.

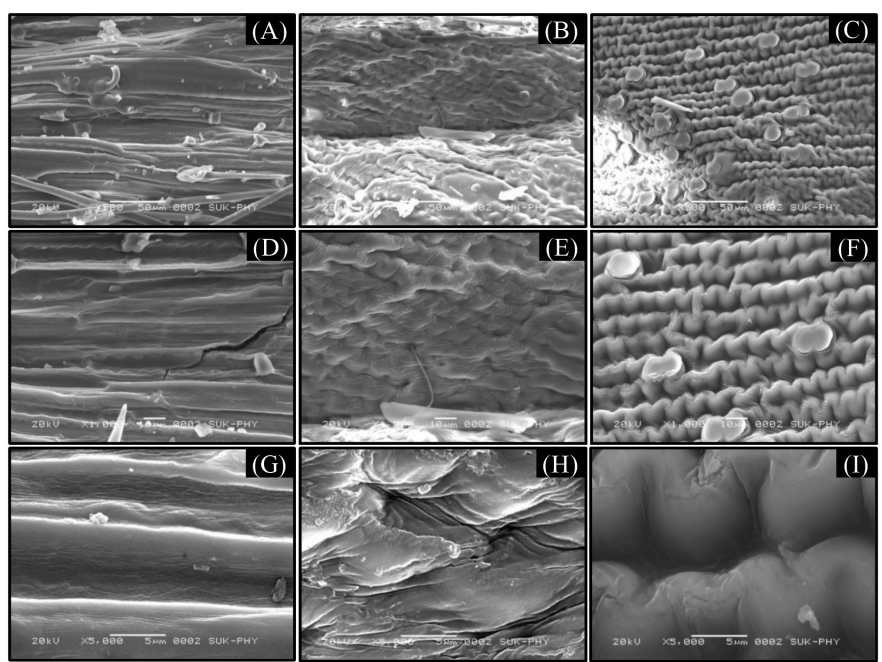

Fig.4. Scanning electron microscopic images of the substrate. Untreated sorghum husk (SH) (A: $\times 500$, D: $\times 1000$, G: $\times 5000)$; Biologically pretreated SH $($ BPSH) $(\mathrm{B}: \times 500, \mathrm{E}: \times 1000, \mathrm{H}: \times 5000)$; and BPSH residue post enzymatic hydrolysis (BPSH-EH) $(\mathrm{C}: \times 500, \mathrm{~F}: \times 1000, \mathrm{I}: \times 5000)$.

\section{Conclusions}

The present study explored the biological pretreatment of SH using $P$. chrysosporium (MTCC 4955). The delignification in response to the biological pretreatment significantly enhanced the hydrolysis yield as compared to untreated SH. The mixture of hexose and pentose sugars produced during the enzymatic hydrolysis was utilized by the $S$. cerevisiae and $P$. tannophilus to produce bioethanol. The surface characterization of SH, BPSH, and BPSH-EH with FTIR, XRD, and SEM revealed the changes in crystallinity, functional groups, and surface topology when compared to untreated SH. The ethanol production from separate fermentation and co-fermentation of BPSH hydrolysate was higher than that of SH hydrolysate. Therefore, the effectiveness of biological pretreatment for the saccharification of lignocellulosic waste biomass like SH can be concluded and this approach could be recommended to augment biofuel production. Moreover, secondary pollution problem caused by the conventional pretreatment processes for ethanol production from $\mathrm{SH}$ could be avoided with the application of biological pretreatment.

\section{Acknowledgements}

Pankajkumar R. Waghmare would like to acknowledge University Grants Commission (UGC), New Delhi for providing financial assistance through UGC-NET-SRF fellowship during this research work. Thanks are also due to UGC, Special Assistance Program (SAP), and the Departmen of Biochemistry Grant No. (SU/EST/PG/1328) for funding and infrastructure.

\section{References}

[1] Adney, B., Baker, J., 1996. Measurement of cellulase activities. Lab Anal. Proced. 6(465)

[2] AOAC., 1990a. AOAC method 973.18 Fiber (Acid Detergent) and Lignin in Animal Feeds, in: Helrick, K., editor, Official Method of Analysis of the Association of Official Analytical Chemists, 15th ed. Arlington, VA: Association of Official Analytical Chemists. 82.

[3] AOAC., 1990b. AOAC method 942.05-Ash in Animal Feeds, in: Helrick, K., editor, Official Method of Analysis of the Association of Official Analytical Chemists, 15th ed. Arlington, VA: Association of Official Analytical Chemists. 70.

[4] Bansal, N., Tewari, R., Soni, R., Soni, S.K., 2012. Production of cellulases from Aspergillus niger NS-2 in solid state fermentation on agricultural and kitchen waste residues. Waste Manage. 32(7), 13411346.

[5] Bateni, H., Karimi, K., 2016. Biorefining of Eruca sativa plant for efficient biofuel production. RSC Adv. 6(41), 34492-34500.

[6] Bateni, H., Bateni, F., Able, C., Noori, M.S., 2017. Biorefinery of safflower seeds in a sequential process for effective use of the substrate for biofuel production. Waste Biomass Valorization. 1-11.

[7] Bateni, H., Saraeian, A., Able, C., 2017. A comprehensive review on biodiesel purification and upgrading. Biofuel Res. J. 4(3), 668-690.

[8] Binod, P., Satyanagalakshmi, K., Sindhu, R., Janu, K.U., Sukumaran, R.K., Pandey, A., 2012. Short duration microwave assisted pretreatment enhances the enzymatic saccharification and fermentable sugar yield from sugarcane bagasse. Renew. Energy. 37(1), 109-116.

[9] Cao, N.J., Krishnan, M.S., Du, J.X., Gong, C.S., Ho, N.W.Y., Chen, Z.D., Tsao, G.T., 1996. Ethanol production from corn cob pretreated by the ammonia steeping process using genetically engineered yeast. Biotechnol. Lett. 18(9), 1013-1018

[10] Chen, M., Xia, L., Xue, P., 2007. Enzymatic hydrolysis of corncob and ethanol production from cellulosic hydrolysate. Int. Biodeterior. Biodegrad. 59(2), 85-89.

[11] Chongkhong, S., Lolharat, B., Chetpattananondh, P., 2012. Optimization of ethanol production from fresh jackfruit seeds using Response Surface Methodology. J. Sust. Energy Environ. 3, 97-101.

[12] Colom, X., Carrillo, F., 2002. Crystallinity changes in lyocell and viscose-type fibres by caustic treatment. Eur. Polym. J. 38(11), 2225 2230

[13] Fackler, K., Stevanic, J.S., Ters, T., Hinterstoisser, B., Schwanninger, M., Salmén, L., 2011. FT-IR imaging microscopy to localise and characterise simultaneous and selective white-rot decay within spruce wood cells. Holzforschung. 65(3), 411-420.

[14] Fan, L.T., Gharpuray, M.M., Lee, Y.H., 1987. Cellulose Hydrolysis. Springer-Verlag, Berlin Heidelberg.

[15] Fischer, G., Hizsnyik, E., Prieler, S., Shah, M., van Velthuize, V.H., 2009. Biofuels and food security. Implications of an accelerated biofuels production. Summary of the OFID prepared by IIASA. OFID Pamphlet Series 38.

[16] French, A.D., Cintrón, M S., 2013. Cellulose polymorphy, crystallite size, and the Segal Crystallinity Index. Cellulose. 20(1), 583-588. 
[17] Gan, Q., Allen, S.J., Taylor, G., 2003. Kinetic dynamics in heterogeneous enzymatic hydrolysis of cellulose: an overview, an experimental study and mathematical modeling. Process Biochem. 38(7), 1003-1018

[18] Havannavar, R.B., Geeta, G.S., 2007. Bioethanol production from enzyme hydrolysed agroresidues. Karnataka J. Agric. Sci. 20(4), 871 872 .

[19] Himmel, M.E., Ding, S.Y., Johnson, D.K., Adney, W.S., Nimlos, M.R., Brady, J.W., Foust, T.D., 2007. Biomass recalcitrance: engineering plants and enzymes for biofuels production. Science. 315(5813), 804807.

[20] Jeffries, T.W., Grigoriev, I.V., Grimwood, J., Laplaza, J.M., Aerts, A., Salamov, A., Schmutz, J., Lindquist, E., Dehal, P., Shapiro, H., Jin, Y.S., Passoth, V., Richardson, P.M., 2007. Genome sequence of the lignocellulose-bioconverting and xylose-fermenting yeast Pichia stipites. Nat. Biotechnol. 25(3), 319-326.

[21] Karimi, K., Taherzadeh, M.J., 2016. A critical review of analytical methods in pretreatment of lignocelluloses: composition, imaging, and crystallinity. Bioresour. Technol. 200, 1008-1018.

[22] Keeney, R., Hertel, T.W., 2009. The indirect land use impacts of United States biofuel policies: the importance of acreage, yield, and bilateral trade responses. Am. J. Agric. Econ. 91(4), 895-909.

[23] Kim, T.H., Lee, Y.Y., 2005. Pretreatment of corn stover by soaking in aqueous ammonia. Twenty-Sixth Symp. Biotechnol. Fuels Chem. 11191132.

[24] Kshirsagar, S.D., Saratale, G.D., Saratale, R.G., Govindwar, S.P., Oh, M.K., 2016. An isolated Amycolatopsis sp. GDS for cellulase and xylanase production using agricultural waste biomass. J. Appl. Microbiol. 120(1), 112-125.

[25] Kumar, R., Tabatabaei, M., Karimi, K., Sárvári Horváth, I., 2016. Recent updates on lignocellulosic biomass derived ethanol-a review. Biofuel Res. J. 3(1), 347-356.

[26] Lee, J.W., Gwak, K.S., Park, J.Y., Park, M.J., Choi, D.H., Kwon, M., Choi, I.G., 2007. Biological pretreatment of softwood Pinus densiflora by three white rot fungi. J. Microbiol. 45(6), 485-491.

[27] Lee, J., Lee, S.M., Hong, E.J., Jeung, E.B., Kang, H.Y., Kim, M.K., Choi, I.G., 2006. Estrogenic reduction of styrene monomer degraded by Phanerochaete chrysosporium KFRI 20742. J. Microbiol. 44(2), 177184.

[28] Lionetto, F., Del Sole, R., Cannoletta, D., Vasapollo, G., Maffezzoli, A., 2012. Monitoring wood degradation during weathering by cellulose crystallinity. Materials. 5(10), 1910-1922.

[29] Liu, X.L., Zeng, G.M., Tang, L., Zhong, H., Wang, R.Y., Fu, H.Y., Liu, Z.F., Huang, H.L., Zhang, J.C., 2008. Effects of dirhamnolipid and SDS on enzyme production from Phanerochaete chrysosporium in submerged fermentation. Process Biochem. 43(11), 1300-1303.

[30] Mani, S., Tabil, L.G., Sokhansanj, S., 2006. Effects of compressive force, particle size and moisture content on mechanical properties of biomass pellets from grasses. Biomass Bioenergy. 30(7), 648-654.

[31] Millati, R., Syamsiah, S., Niklasson, C., Cahyanto, M.N., Ludquist, K., Taherzadeh, M.J., 2011. Biological pretreatment of lignocelluloses with white-rot fungi and its applications: a review. BioResources. 6(4), 52245259.

[32] Miller, G.L., 1959. Use of dinitrosalicyclic reagent for determination of reducing sugar. Anal. Chem. 31(3), 426-428.

[33] Mosier, N., Wyman, C., Dale, B., Elander, R., Lee, Y.Y., Holtzapple, M., Ladisch, M., 2005. Features of promising technologies for pretreatment of lignocellulosic biomass. Bioresour. Technol. 96(6), 673686.

[34] Nitisinprasert, S., Temmes, A., 1991. The characteristics of a new nonspore-forming cellulolytic mesophilic anaerobe strain CM126 isolated from municipal sewage sludge. J. Appl. Bacteriol. 71(2), 154-161.

[35] Noori, M.S., Karimi, K., 2016. Detailed study of efficient ethanol production from elmwood by alkali pretreatment. Biochem. Eng. J. 105, 197-204.

[36] Noori, M.S., Karimi, K., 2016. Chemical and structural analysis of alkali pretreated pinewood for efficient ethanol production. RSC Adv. 6(70), 65683-65690.
[37] Oh, S.Y., Yoo, D.I., Shin, Y., Seo, G., 2005. FTIR analysis of cellulose treated with sodium hydroxide and carbon dioxide. Carbohydr. Res. 340(3), 417-428.

[38] Park, S., Baker, J.O., Himmel, M.E., Parilla, P.A., Johnson, D.K., 2010. Cellulose crystallinity index: measurement techniques and their impact on interpreting cellulase performance. Biotechnol. Biofuels. 3(1), 10

[39] Ramle, S.F.M., Sulaiman, O., Hashim, R., Arai, T., Kosugi, A., Abe, H., Murata, Y., Mori, Y., 2012. Characterization of parenchyma and vascular bundle of oil palm trunk as function of storage time. Lignocellulose. 1(1), 33-44.

[40] Rogalski, J., Szczodrak, J., Janusz, G., 2006. Manganese peroxidase production in submerged cultures by free and immobilized mycelia of Nematoloma frowardii. Bioresour. Technol. 97(3), 469-476.

[41] Saratale, G.D., Kshirsagar, S.D., Saratale, R.G., Govindwar, S.P., Oh, M.K., 2015. Fermentative hydrogen production using sorghum husk as a biomass feedstock and process optimization. Biotechnol. Bioprocess Eng. 20(4), 733-743

[42] Saratale, G.D., Saratale, R.G., Oh, S.E., 2012. Production and characterization of multiple cellulolytic enzymes by isolated Streptomyces sp. MDS. Biomass Bioenergy. 47, 302-315.

[43] Segal, L.G.J.M.A., Creely, J.J., Martin Jr, A.E., Conrad, C.M., 1959. An empirical method for estimating the degree of crystallinity of native cellulose using the X-ray diffractometer. Text. Res. J. 29(10), 786-794.

[44] Sindhu, R., Binod, P., Pandey, A., 2016. Biological pretreatment of lignocellulosic biomass-an overview. Bioresour. Technol. 199, 7682.

[45] Singh, A., Bishnoi, N.R., 2012. Optimization of enzymatic hydrolysis of pretreated rice straw and ethanol production. Appl. Microbiol. Biotechnol. 93(4), 1785-1793.

[46] Singh, D., Chen, S., 2008. The white-rot fungus Phanerochaete chrysosporium: conditions for the production of lignin-degrading enzymes. Appl. Microbiol. Biotechnol. 81(3), 399-417.

[47] Su, M.Y., Tzeng, W.S., Shyu, Y.T., 2010. An analysis of feasibility of bioethanol production from Taiwan sorghum liquor waste. Bioresour. Technol. 101(17), 6669-6675

[48] Sun, Y., Cheng, J., 2002. Hydrolysis of lignocellulosic materials for ethanol production: a review. Bioresour. Technol. 83(1), 1-11.

[49] Taniguchi, M., Suzuki, H., Watanabe, D., Sakai, K., Hoshino, K. Tanaka, T., 2005. Evaluation of pretreatment with Pleurotus ostreatus for enzymatic hydrolysis of rice straw. J. Biosci. Bioeng. 100(6), 637-643.

[50] Taherzadeh, M.J., Karimi, K., 2007. Enzyme-based hydrolysis processes for ethanol from lignocellulosic material: a review. BioResources. 2(4), 707-738.

[51] Taherzadeh, M.J., Karimi, K., 2008. Pretreatment of lignocellulosic wastes to improve ethanol and biogas production: a review. Int. J. Mol. Sci. 9(9), 1621-1651.

[52] van Soest, P.V., Robertson, J.B., Lewis, B.A., 1991. Methods for dietary fiber, neutral detergent fiber, and non-starch polysaccharides in relation to animal nutrition. J. Dairy Sci. 74(10), 3583-3597.

[53] Velazquez-Lucio, J., Rodríguez-Jasso, R.M., Colla, L.M., SáenzGalindo, A., Cervantes-Cisneros, D.E., Aguilar, C.N., Fernandes, B.D., Ruiz, H.A., 2018. Microalgal biomass pretreatment for bioethanol production: a review. Biofuel Res. J. 5(1), 780-791.

[54] Waghmare, P.R., Kadam, A.A., Saratale, G.D., Govindwar, S.P., 2014. Enzymatic hydrolysis and characterization of waste lignocellulosic biomass produced after dye bioremediation under solid state fermentation. Bioresour. Technol. 168, 136-141.

[55] Wang, L., Han, G., Zhang, Y., 2007. Comparative study of composition, structure and properties of Apocynum venetum fibers under different pretreatments. Carbohydr. Polym. 69(2), 391-397.

[56] Williams, M.B., Reese, H.D., 1950. Colorimetric determination of ethyl alcohol. Anal. Chem. 22(12), 1556-1561.

[57] Yang, S., Li, J., Zheng, Z., Meng, Z., 2009. Lignocellulosic structural changes of Spartina alterniflora after anaerobic mono-and co-digestion. Int. Biodeterior. Biodegrad. 63(5), 569-575. 
[58] Yeoman, C.J., Han, Y., Dodd, D., Schroeder, C.M., Mackie, R.I., Cann, I.K., 2010. Chapter1-thermostable enzymes as biocatalysts in the biofuel industry. Adv. Appl. Microbiol. 70, 1-55.

[59] Yu, H., Guo, G., Zhang, X., Yan, K., Xu, C., 2009. The effect of biological pretreatment with the selective white-rot fungus Echinodontium taxodii on enzymatic hydrolysis of softwoods and hardwoods. Bioresour. Technol. 100(21), 5170-5175.

[60] Zeng, J., Singh, D., Chen, S., 2011. Biological pretreatment of wheat straw by Phanerochaete chrysosporium supplemented with inorganic salts. Bioresour. Technol. 102(3), 3206-3214.
[61] Zhang, Y., Xu, J.L., Xu, H.J., Yuan, Z.H., Guo, Y., 2010. Cellulase deactivation based kinetic modeling of enzymatic hydrolysis of steam-exploded wheat straw. Bioresour. Technol. 101(21), 82618266.

[62] Zhou, D., Zhang, L., Guo, S., 2005. Mechanisms of lead biosorption on cellulose/chitin beads. Water Res. 39(16), 3755-3762. 